\title{
OBTENCIÓN DE PLANTAS LIBRES DE VIRUS DE ASPARAGUS OFFICINALIS L. "ESPÁRRAGO"IN VITRO
}

\author{
Mauro QUIÑONES AGUILAR \\ Universidad Ricardo Palma \\ mauro.quinones@urp.edu.pe
}

Renzo RIBOTY ILAS

Universidad Ricardo Palma

rribotyi@urp.edu.pe

\section{RESUMEN}

La presente investigación, busca obtener plantas libres de enfermedades patógenas (virus principalmente) de Asparagus officinalis L. "espárrago", aplicando los métodos biotecnológicos del cultivo in vitro de meristemos. Como explante se utilizaron fragmentos de la parte apical de turriones, los cuales fueron lavados y sumergidos en alcohol al $70 \%$ por 2 minutos, seguido en hipoclorito de sodio $(\mathrm{NaClO})$ al $2 \%$ por 10 minutos, terminado el proceso, los meristemos fueron asilados utilizando estereoscopio binocular e introducidos en el medio Murashige y Skoog (MS) suplementado con 0,$5 ; 1,0$ y $1,5 \mathrm{mg} / \mathrm{L}$ de 6-Bencil Aminopurina (6-BAP) e incubadas en cámara de cultivo con fotoperiodo de 16 horas luz y 8 horas de oscuridad, con una temperatura de $22^{\circ} \mathrm{C}$. A los 28 días de cultivo, Se logró obtener, en el medio suplementados con $0,5 \mathrm{mg} / \mathrm{L}$ de BAP 8 brotes de 0,$4 ; 1,6$ y 2,8 $\mathrm{cm}$. de longitud con 8 cladófilos desarrollados, mientras que, en el medio suplementado con 1,0 mg/l de BAP se obtuvo 6 brotes de 0,9 y 1,4 cm. de longitud sin cladófilos y en el medio de cultivo con 1,5 mg/l de 6-BAP solo de se obtuvo 1 brote y 5 cladófilos.

\section{PALABRAS CLAVE}

Asparagus officinalis L./Micropropagación / 6-Bencil Aminopurina/ Meristemo/ Cultivo in vitro

\section{OBTAINING VIRUS FREE PLANTS FROM ASPARAGUS OFFICINALIS L.} "Asparagus" IN VITRO

\section{ABSTRACT}

This work attempts to obtain free virus Asparagus officinalis L. "garden asparagus" plants, applying the biotechnological methods of the in vitro meristem culture. Axillary buds were used as explants, and were sterilized, isolated, cultivated in the basal medium Murashige \& Skoog (MS) at 3 different concentrations $(0,5 ; 1,0 \& 1,5 \mathrm{mg} / \mathrm{L})$ of the phytohormone 6-Bencil Aminopurine (6-BAP), and incubated under controlled conditions in a cultivation room. As a result, 8 shoots \& 8 cladodes, 6 shoots with no cladodes and 1 shoot \& 5 cladodes were obtained in the culture mediums supplemented with the 3 concentrations of 6-BAP respectively.

\section{KEY WORDS}

Asparagus officinalis L. / micropropagation / 6-Benzyl Aminopurine/ Meristem

Recibido: $27 / 03 / 2019$

Aprobado: 16/05/2019 


\section{INTRODUCCIÓN}

A

sparagus officinalis L., "espárrago", es una planta perenne y dioica de la familia de las Liliáceas, género Asparagus. Este género engloba aproximadamente 200 especies, de las cuales solo $A$. officinalis $L$. es de uso alimenticio. Las plantas de espárrago macho son heterocigotos $(\mathrm{Mm})$ y las hembras homocigotos $(\mathrm{mm})$, siendo la primera de más alta productividad en relación al tamaño y número de turiones (Matsubara, S. 1973).

El espárrago es un producto agrícola de alto valor económico para el Perú, siendo la producción del mismo una actividad importante en los valles costeros, donde se cultivan dos tipos de espárragos: el espárrago blanco, para transformación en conservas, y el espárrago verde, para la exportación en fresco a distintos mercados del mundo. Tanto el espárrago blanco como el verde son ricos en fibras y proteínas. También poseen un alto contenido de fósforo y son considerados como antioxidantes intermedios debido a la presencia de los fenoles (Petrel, M. et al. 2007).

Sin embargo, el cultivo de espárrago enfrenta dificultades relacionadas a su productividad, las cuales se encuentran asociadas con el manejo científico-técnico, como la renovación de los campos de cultivo que no se realizan sino hasta después de 10 - 20 años. Por otra parte, las plantas hembras sembradas por desconocimiento generan semillas que a su vez forman nuevas plantas no deseadas que acortan el espacio entre plantas y consumen los nutrientes.

Otro de los problemas que enfrenta las plantaciones del espárrago es el ataque por enfermedades causadas tanto por virus, que ocasionan la formación de un menor número de turiones y disminuye el vigor del desarrollo de los mismos, como de hongos como la fusariosis (asociación de hongos) del género Fusarium, la cual causa podredumbre de las raíces resultando en la muerte de las plantas (Blok, W. \& Bollen, G. 1995).

Durante muchos años se viene intentando uniformizar la producción del espárrago con el uso de plantas machos híbridas resistentes a enfermedades patógenas (virus y hongos) y de alto rendimiento, sin embargo, estos intentos aún no han dado los resultados esperados. Como una de las alternativas para resolver este problema, se considera la propagación clonal in vitro de plantas selectas.

La propagación clonal in vitro es una de las técnicas biotecnológicas, que se fundamenta en la obtención de plantas completas a partir de meristemos, y consiste en la introducción de yemas al medio de cultivo MS (Murashige \& Skoog. 1962), donde se inicia la organogénesis directa. Las plantas obtenidas in vitro son luego sembradas en medios de cultivo suplementados con citoquininas para la inducción de brotes adventicios, los cuales pueden ser subcultivados sucesivamente hasta lograr la propagación masiva. Las plántulas son finalmente enraizadas y aclimatadas a condiciones ambientales.

\section{MATERIALES Y MÉTODOS}

Asparagus officinalis L., "espárrago" (plantas madre), procedentes del Distrito de Ingenio de la provincia de Nazca, fueron establecidas en el invernadero de la 
Universidad Ricardo Palma en condiciones controladas y nutrición adecuada. Estas fueron llevadas al Laboratorio de Biotecnología Vegetal, donde se tomaron explantes y/o fragmentos de $5 \mathrm{~cm}$ de la parte apical de turiones, luego fueron lavados con agua de caño con detergente y enjuagados con agua destilada. A continuación, fueron sumergidos en alcohol de $70 \%$ por 2 minutos, seguido en hipoclorito de Sodio al $2 \%$ por 10 minutos y enjuagados 3 veces en agua destilada previamente esterilizada con un intervalo de cinco minutos de enjuague a enjuague. Terminado este proceso, se aislaron los meristemos entre $0,1-0,2 \mathrm{~cm}$, utilizando estereoscopio binocular marca Leica e instrumentos de disección previamente flameados en mechero de alcohol y luego, fueron introducidos en tubos de vidrio Pyrex de 2,5 x $15 \mathrm{~cm}$ con medio de cultivo basal Murashige y Skoog 1962 (MS) suplementado con 3 concentraciones (0,5; 1,0 y 1,5 mg/L.) de 6-Bencilaminopurina (6-BAP). A continuación, los tubos fueron sellados con Parafilm, rotulados y llevados a la sala de transferencia donde se establecieron en condiciones de fotoperiodo de 16 horas de luz y 8 horas de oscuridad, a una temperatura de $22^{\circ} \mathrm{C}$. Todo el proceso de introducción in vitro se desarrolló dentro de la Cámara de flujo laminar.

\section{RESULTADOS}

\section{Desarrollo de brotes y cladófilos}

De los meristemos aislados $(0,1$ a $0.2 \mathrm{~cm})$, tras 28 días de cultivo, 3 explantes de la concentración de $0,5 \mathrm{mg} / \mathrm{L}$ presentaron entre 2 a 3 brotes, de los cuales 2 desarrollaron 2 y 6 cladófilos. Respecto a la concentración de 1,0 mg/L, 3 explantes formaron entre 1 y 3 brotes, sin embargo, ninguno de los 4 meristemos sembrados a esta concentración evidenció crecimiento de cladófilos. Solo un explante de la concentración de 1,5 mg/L de 6-BAP mostró el desarrollo de 1 brote, mientras que otro explante de la misma concentración desarrolló 5 cladófilos sin la presencia de brotes (Tabla 1 y Figura 1, 2 y 3 ).

\section{Crecimiento de los explantes}

En la concentración de 0,5 mg/L de 6-BAP, los explantes 2, 3 y 4 tuvieron un desarrollo entre 1,6 y $2,8 \mathrm{~cm}$ tras 28 días de desarrollo, sin embargo, el explante 1 solo alcanzó los 0,4 cm de altura. Esta diferencia en el desarrollo puede deberse a un mal manejo durante el aislamiento del domo meristemático, resultando en la siembra in vitro de un explante con una zona de crecimiento dañada o ausente (Gráfica 1). En la concentración de 1,0 mg/L de 6-BAP, los 4 explantes tuvieron un desarrollo entre 0,9 y $1,4 \mathrm{~cm}$ tras 28 días de desarrollo (Gráfica 2). En la concentración de 1,5 mg/L de 6-BAP, los explantes 1, 2 y 4 tuvieron un desarrollo entre 0,7 y 0,9 cm tras 28 días de desarrollo, sin embargo, el explante 3 alcanzó los 2,0 cm de altura (Gráfica 3).

La concentración con mayor crecimiento en altura fue $0,5 \mathrm{mg} / \mathrm{L}$ con un promedio de $1,83 \mathrm{~cm}$ en 4 semanas (Gráfica 1). Las concentraciones de 1,0 y 1,5 mg/L mostraron promedios de crecimiento similares, 1,15 y 1,12 cm respectivamente (Gráfica 2 y 3). 


\begin{tabular}{|c|c|c|c|c|c|c|c|c|c|c|c|}
\hline \multicolumn{2}{|c|}{ Fecha } & \multicolumn{2}{|c|}{0 días } & \multicolumn{2}{|c|}{7 días } & \multicolumn{2}{|c|}{14 días } & \multicolumn{2}{|c|}{21 días } & \multicolumn{2}{|c|}{28 días } \\
\hline $\begin{array}{l}\text { 6-BAP } \\
(\mathrm{mg} / \mathrm{L})\end{array}$ & Repetición & $\begin{array}{c}\text { No } \\
\text { brotes }\end{array}$ & $\begin{array}{c}\text { No } \\
\text { cladófilos }\end{array}$ & $\begin{array}{c}\text { No } \\
\text { brotes }\end{array}$ & $\begin{array}{c}\text { No } \\
\text { cladófilos }\end{array}$ & $\begin{array}{c}\text { № } \\
\text { brotes }\end{array}$ & $\begin{array}{c}\text { No } \\
\text { cladófilos }\end{array}$ & $\begin{array}{c}\text { № } \\
\text { brotes }\end{array}$ & $\begin{array}{c}\text { No } \\
\text { cladófilos }\end{array}$ & $\begin{array}{c}\text { № } \\
\text { brotes }\end{array}$ & № cladófilos \\
\hline \multirow{4}{*}{0,5} & 1 & 0 & 0 & 0 & 0 & 0 & 0 & 0 & 0 & 0 & 0 \\
\hline & 2 & 0 & 0 & 0 & 0 & 1 & 0 & 2 & 0 & 2 & 0 \\
\hline & 3 & 0 & 0 & 0 & 0 & 2 & 0 & 2 & 2 & 3 & 2 \\
\hline & 4 & 0 & 0 & 0 & 0 & 1 & 2 & 3 & 4 & 3 & 6 \\
\hline \multirow{4}{*}{1,0} & 1 & 0 & 0 & 0 & 0 & 1 & 0 & 1 & 0 & 2 & 0 \\
\hline & 2 & 0 & 0 & 0 & 0 & 1 & 0 & 1 & 0 & 3 & 0 \\
\hline & 3 & 0 & 0 & 0 & 0 & 0 & 0 & 0 & 0 & 1 & 0 \\
\hline & 4 & 0 & 0 & 0 & 0 & 0 & 0 & 0 & 0 & 0 & 0 \\
\hline \multirow{4}{*}{1,5} & 1 & 0 & 0 & 0 & 0 & 0 & 0 & 0 & 0 & 0 & 0 \\
\hline & 2 & 0 & 0 & 0 & 0 & 1 & 0 & 1 & 0 & 1 & 0 \\
\hline & 3 & 0 & 0 & 0 & 0 & 0 & 0 & 0 & 0 & 0 & 0 \\
\hline & 4 & 0 & 0 & 0 & 0 & 0 & 0 & 0 & 2 & 0 & 5 \\
\hline
\end{tabular}

Tabla 1. Desarrollo de brotes y cladófilos durante 28 días en MS suplementado con $0.5,1.0$ y $1.5 \mathrm{mg} / \mathrm{L}$ de $6-B A P$.

\begin{tabular}{|c|c|c|c|c|c|}
\hline $\begin{array}{c}\text { 6-BAP } \\
\text { (mg/L) }\end{array}$ & 0 días & 7 días & 14 días & 21 días & 28 días \\
\hline 0,5 & & & & & \\
\hline
\end{tabular}

Figura 1. Secuencia del desarrollo del meristemo de A. officinalis L. en MS suplementado con 0,5 mg de 6-BAP: brotes y cladófilos.

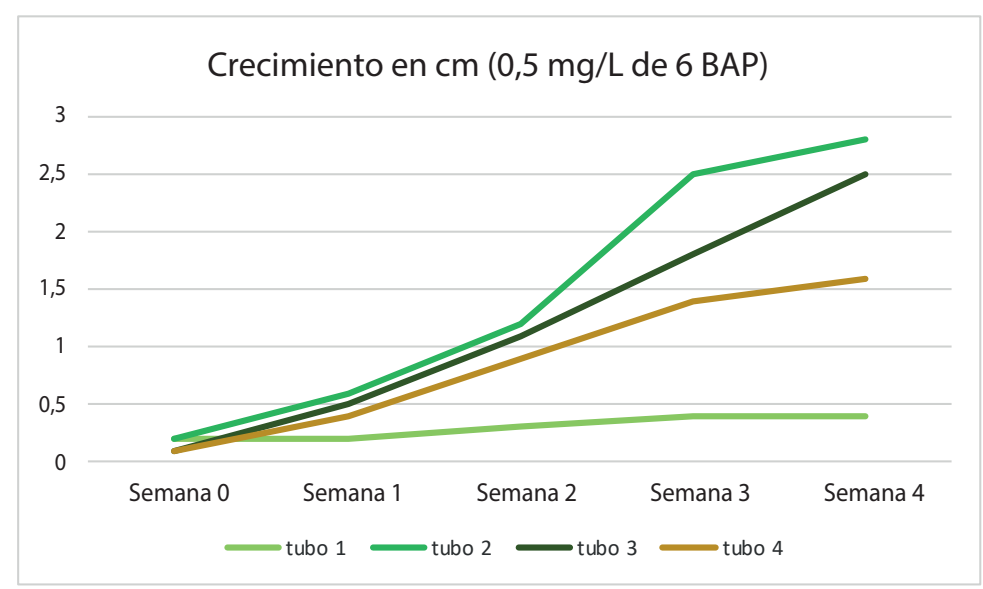

Gráfica 1. Crecimiento en $\mathrm{cm}$ durante 4 semanas en MS suplementado con 0,5 $\mathrm{mg} / \mathrm{L}$ de 6-BAP. 


\begin{tabular}{|c|c|c|c|c|c|}
\hline $\begin{array}{c}\text { 6-BAP } \\
\text { (mg/L) }\end{array}$ & 0 días & 7 días & 14 días & 21 días & 28 días \\
\hline 1,0 & & & & & \\
\hline
\end{tabular}

Figura 2. Secuencia del desarrollo del meristemo de A. officinalis L. en MS suplementado con 1,0 mg de 6-BAP a: brotes

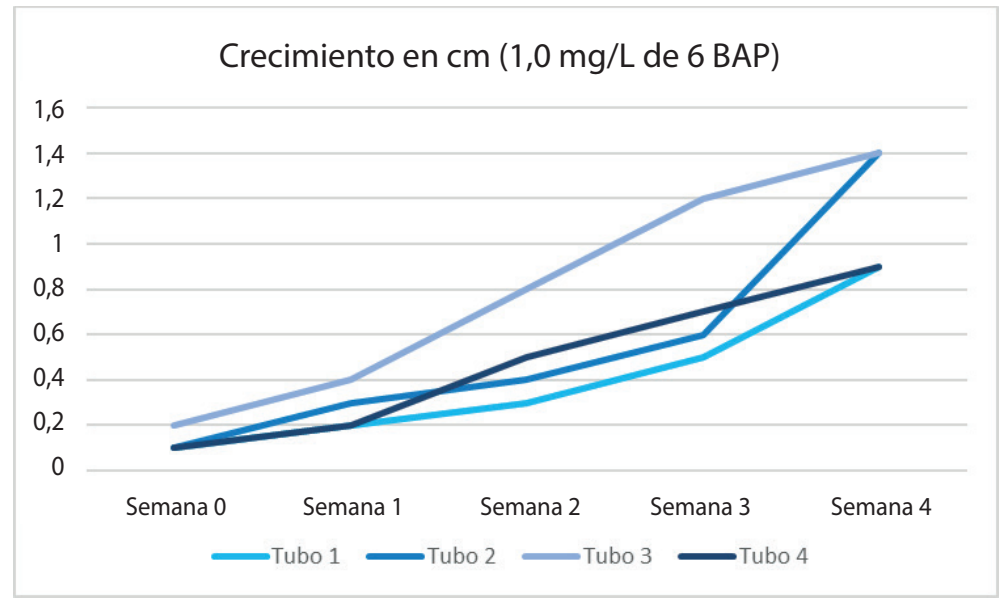

Gráfica 2. Crecimiento en cm durante 4 semanas en MS suplementado con 1,0 $\mathrm{mg} / \mathrm{L}$ de 6-BAP.

\begin{tabular}{|c|c|c|c|c|c|}
\hline $\begin{array}{c}\text { 6-BAP } \\
\text { (mg/L) }\end{array}$ & 0 días & 7 días & 14 días & 21 días & 28 días \\
\hline 1,5 & & & & & \\
\hline
\end{tabular}

Figura 3. Secuencia del desarrollo del meristemo de A. officinalis L. en MS suplementado con 1,5 mg de 6-BAP: brotes y cladófilos. 


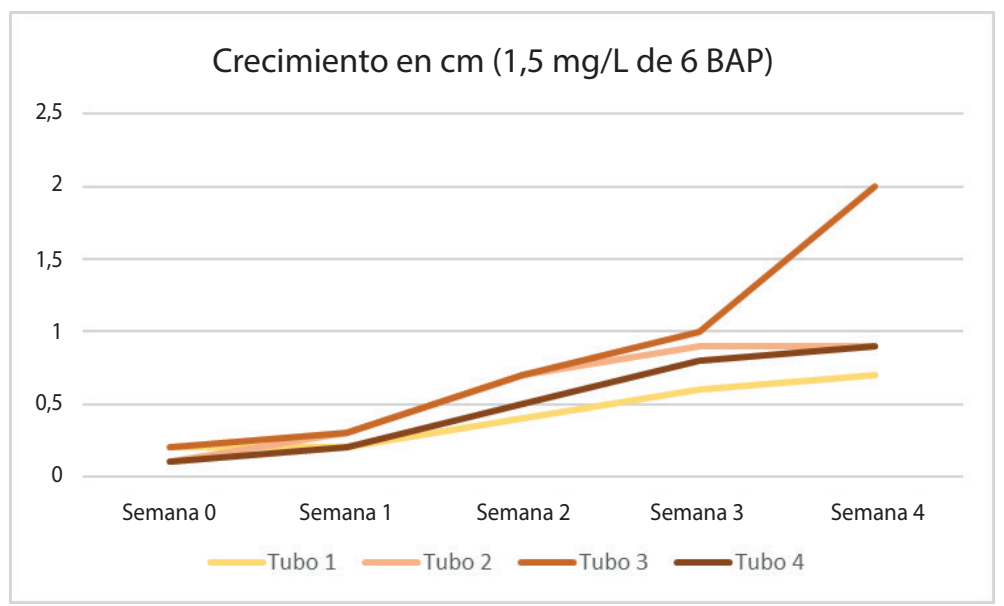

Gráfica 3. Crecimiento en cm durante 4 semanas en MS suplementado con 1,5 $\mathrm{mg} / \mathrm{L}$ de 6-BAP.

\section{DISCUSIÓN}

El espárrago es una planta donde la probabilidad de contaminación en los medios de cultivo es alta, debido a las bacterias y esporas que arrastran las escamas del turión mientras este emerge de la tierra (Asprelli, P. etal. 2002). En el presente trabajo, ninguno de los 12 explantes manifestó contaminación luego de la introducción in vitro de los meristemos, demostrando la eficacia del protocolo de esterilización utilizado.

El uso de la citoquinina 6-Bencil Aminopurina (6-BAP) se fundamenta por su efecto sobre la elongación y crecimiento de meristemos, induciendo el desarrollo de brotes de aspecto saludable (Sharan, M. et al. 2011). Los meristemos apicales, como indica Sharan, M. et al. (2011), poseen una mayor capacidad de regeneración en comparación con los meristemos laterales, desarrollando un mayor número de brotes, sin embargo, como explantes, se utilizaron meristemos laterales, debido a la falta de meristemos apicales suficientes.

Se utilizó un fotoperiodo de 16 horas de luz y 8 horas de oscuridad debido a que este influye positivamente en la formación de brotes de buen aspecto y la elongación de los explantes (González, S. 2010).

En la concentración de 0,5 mg/L de 6-BAP, se obtuvieron un total de 8 brotes, con un promedio de 2 brotes por explante, los cuales fueron vigorosos y de rápido crecimiento, por lo tanto, útiles para la Micropropagación (Figura 2). Las concentraciones de 1,0 y $1,5 \mathrm{mg} / \mathrm{L}$ desarrollaron un promedio de 1,5 y 0,25 brotes por explante respectivamente, los cuales eran más cortos, gruesos y deformes (Figura 3 y 4). Estos resultados coinciden con los obtenidos por Slabbert et al. (1990), quien obtuvo el mayor promedio de brotes aptos para la micropropagación a partir de una concentración baja de 6-BAP $(0,1 \mathrm{mg} / \mathrm{L})$, llegando a tener un promedio de 5 brotes por explante. La hormona 6-BAP también puede ser utilizada junto a otras fitohormonas como la auxinaácido naftalenacético (ANA), logrando un mejor 
resultado en el desarrollo de brotes de plantas del género Asparagus, como se pudo observar en Reddy, K.N. et al. (2007).

La concentración de $0,5 \mathrm{mg} / \mathrm{L}$ desarrolló 8 cladófilos, mientras que en la concentración de 1,5 mg/L se observaron 5 cladófilos (Figura 2 y 4). Ninguno de los explantes de la concentración de 1,0 mg/L desarrolló cladófilos (Figura 3). Estos resultados son opuestos a los obtenidos por Slabbert et al. (1990), quien no logró inducir el desarrollo de estas estructuras en ninguna de sus concentraciones de 6-BAP utilizadas $(0,1 ; 0,5 ; 1,0$ y 2,0 mg/L). Los cladófilos son esenciales para la supervivencia de las plántulas durante la aclimatación a condiciones ambientales.

El crecimiento en cm de los explantes fue mayor en la concentración de 0,5 mg/L de 6-BAP, con un promedio de $1,83 \mathrm{~cm}$ tras 4 semanas de seguimiento, mientras que el promedio para 1,0 y 1,5 mg/L disminuyó de manera proporcional con promedios de 1,15 y $1,12 \mathrm{~cm}$ respectivamente, demostrando una relación inversamente proporcional entre el crecimiento en $\mathrm{cm}$ y la concentración de 6-BAP (Gráficas 1-3 y Figuras 2-4). Según los resultados de Sharan, M. et al. (2011), la adición al medio de un $15 \%$ de agua de coco aumenta significativamente la elongación de los explantes además de aumentar el número de brotes desarrollados en explantes de A. racemosus.

\section{CONCLUSIONES}

El protocolo de esterilización de los explantes fue eficiente, evitándose la contaminación en los 12 medios de cultivo de meristemos de Asparagus officinalis L.

Las plantas de espárrago desarrollaron un mayor número promedio de brotes (2) y cladófilos (4) con la menor concentración $(0,5 \mathrm{mg} / \mathrm{L})$ del medio de cultivo MS suplementado con 6-Bencil Aminopurina. Así mismo, el crecimiento en cm se vio afectado de manera inversamente proporcional a la concentración de la hormona 6-BAP, siendo la concentración menor la que obtuvo un promedio de crecimiento en $\mathrm{cm}$ mayor $(1,83 \mathrm{~cm})$.

\section{BIBLIOGRAFÍA}

Asprelli, P.; Cravero, V.; Gatti, I.; Cointry, E. (2002). Micropropagación de plantas elite de espárrago. Revista científica agropecuaria 6: 17-23.

Aynsley, J. \& Marston, M. (1975). Aerial Plantlet Formation in Asparagus officinalis L. Scientia Horticulturae, 3(2): 149-155.

Chang, D. \& Peng, K. (1996). Phloroglucinoland Tryptone Enhace in vitro Rooting and Survival Rate of Asparagus Nodal Sections. Acta Hortic. 415, 411-416.

Conner, J.; Abernethy, D.; Falloon, P. (1992). Importance of in vitro Storage Root Development for the Successful Transfer of Micropropagated Asparagus Plants to Greenhouse Conditions. New Zealand Journal of Crop and Horticultural Science. Volume 20 (4): 477-481. 
Blok, W. \& Bollen, G. (1995). Fungi on Roots and Stem Bases of Asparagus in the Netherlands: Species and Pathogenicity. European Journal of Plant Pathology, 101: 15-24.

Khunachak, A.; Chin, C.; Le, T.; Gianfagna, T. (1987). Promotion of Asparagus Shoot and Root Growth by Growth Retardants. Plant Cell, Tissue and Organ Culture, 11(2): 97-110.

Esqueda, M.; Robert, M.; Gutierrez, A.; Coronado M. (2011). Producción de plantas sobresaliente de espárrago por cultivo de tejido. Estado de Sonora.

Gatti I.; Cravero V.; López F.; Asprelli P.; Firpo I.; García S.; Cointry E. (2001). Creación y Evaluación de Híbridos Clonales de Espárrago. Revista de Investigaciones de la Facultad de Ciencias Agrarias. Año2. №2. Pp. 037-050.

Murashige, T. \& Skoog, F. (1962). A Revised Medium for Rapid Growth and Bioassays with Tobacco Tissue Cultures. Physiol Plant. (15): 473-497.

Petrel, M.; Pérez, V.; Sánchez, M.; López, E.; Obón, C. (2007). Propiedades nutritivas y funcionales de plantas comestibles silvestres de la provincia de Alicante. Depto. De biología aplicada, Universidad Miguel Hernández, Alicante, España.

Pindel A. (2017). Regeneration Capacity of Asparagus Setaceous (Kunth) Jessop Pyramidalis In vitro Cultures. University of Krakow. Acta Sci. Pol. Hortorum Cultus, 16 (1): 85-93.

Reddy, K.; Kumar, A.; Rahiman, B. (2007). Rapid in Vitro Protocol for High Multiple Shoot Induction, Rooting and Flowering in Asparagus racemosus L. Medicinal and Aromatic Plant Science and Biotechnology, 1(2): 274-277.

Regalado J.; Carmona E.; Madrid E.; Moreno R.; Gil J.; Encina C. (2015).Production of "Super-Males" of Asparagus by Anther Culture and its Detection With SSRESTs. Laboratorio de Cultivo de Tejidos y Biotecnología, Instituto de Horticultura Subtropical y Mediterránea La Mayora, CSIC-UMA, 29750 Algarrobo-Costa, Málaga, Spain. Plant Cell Tiss Organ Cult.

Ren, J.; Chen, W.; Knaflewski, M. (2012). Factors Affecting Asparagus (Asparagus officinalis L.) Root Development in vitro. Acta Scientiarum Polonorum. Hortorum Cultus, 11(6).

Sharan, M.; Nene, C.; Sharon, M. (2011). Regeneration of Asparagus racemosus by Shoot Apex and Nodal Explants. Asian J Plant Sci Res (1): 49-56.

Shigeta, J.; Sato, K.; Tanaka, S.; Nakayama, M.; Mii, M. (1996). Efficient Plant Regeneration of Asparagus by Inducing Normal Roots from in vitro Multiplied Shoot Explants Using Gellan Gum and Glucose. Plant Science Volume 113 (1): 99-104.

Slabbert, M.; Lindeque, J.; Ferreira, D. (1990). Rapid in vitro Multiplication of Asparagus. South African Journal of Botany, 56(3), 331-335.

Stajner, N. (2012). Micropropagation of Asparagus by in vitro Shoot Culture. Method in Molecular Biology. Vol 994: 341-351. 